\title{
Harran Ovası Koşullarında Yetiştirilen Mısır Bitkisinde (Zea mays L. indentata) Farklı Ekim Sıklığının Silaj Verimi ve Bazı Tarımsal Özelliklere Etkisi
}

\author{
Timuçin TAŞ ${ }^{1}$ Ayşe Gülgün ÖKTEM² *Abdullah ÖKTEM² \\ ${ }^{1}$ GAP Tarımsal Araştırma Enstitüsü Müdürlüğü, Şanlıurfa, \\ ${ }^{2}$ Harran Üniversitesi Ziraat Fakültesi Tarla Bitkileri Bölümü, Şanlıurfa \\ *Sorumlu yazar e-posta (Corresponding author; e-mail): aoktem@harran.edu.tr
}

\section{Öz}

Bu araştırma ile farkı ekim sıklığı uygulamalarının silajık mısırın verim ve bazı verim unsurlarına etkisini belirlemek amaçlanmıştır. Araştırma 2010, 2011 ve 2012 yıllarında 3 yıl süre ile Harran Ovası koşullarında Şanlıurfa'da yürütülmüştür. Deneme tesadüf blokları deneme deseninde 3 tekrarlamalı olarak kurulmuştur. Samada-07 silajlık mısır çeşidi bitkisel materyal olarak kullanılmıştır. Araştırmada 14285 bitki/da (sıra üzeri $10 \mathrm{~cm}$ ), 10204 bitki/da (sıra üzeri $14 \mathrm{~cm}$ ), 7937 bitki/da (sıra üzeri $18 \mathrm{~cm}$ ), 6493 bitki/da (sıra üzeri $22 \mathrm{~cm}$ ), ve 5494 bitki/da (sıra üzeri $26 \mathrm{~cm}$ ) olmak üzere 5 adet ekim sıklığı kullanılmıştır. Silaj verimi, kuru ot verimi, bitki boyu, sap kalınlığı, yaprak sayısı ve kuru madde oranı bakımından ekim sıklıkları arasında önemli farkııık belirlenmiştir ( $\mathrm{P} \leq 0.01)$. En yüksek silaj verimi $(6884 \mathrm{~kg} / \mathrm{da})$ ve kuru ot verimi $(2131 \mathrm{~kg} / \mathrm{da}) 14286 \mathrm{bitki} / \mathrm{da}$ ekim sıklığında (10 cm sıra üzeri) belirlenirken, en yüksek kuru madde oranı değeri \%29.91 ile 5494 bitki/da (26 cm sıra üzeri) ekim sıklığında bulunmuştur.

Anahtar Kelimeler: Mısır, ekim sıklığı, silaj verimi, GAP, Harran Ovası

\section{Effect of Different Sowing Densities to Silage Yield and Some Agricultural Characteristics of Corn (Zea mays L. indentata) in Harran Plain Conditions}

\begin{abstract}
This study aimed to determine effect of different sowing densities to silage yield and some agricultural characteristics of corn. Study was conducted in Harran Plain-Şanlıurfa conditions according to complete randomized block design with tree replicates in 2010, 2011 and 2012. Samada-07 dent corn silage variety was used in the study. Sowing densities were 14285 plant/da (intra row space $10 \mathrm{~cm}$ ), 10204 plant/da (intra row space $14 \mathrm{~cm}$ ), 7937 plant/da (intra row space $18 \mathrm{~cm}$ ), 6493 plant/da (intra row space $22 \mathrm{~cm}$ ) and 5494 plant/da (intra row space $26 \mathrm{~cm}$ ). Sowing densities were significant at silage yield, dry grass yield, plant height, stem diameter, leaf number and dry matter ratio $(P \leq 0.01)$. The highest silage yield $(6884 \mathrm{~kg} / \mathrm{da})$ and dry grass yield $(2131 \mathrm{~kg} / \mathrm{da})$ were found at 14286 plant/da (10 cm intra row space) sowing density. But the highest dry matter ratio (\%29.91) was obtained from 5494 plant/da (26 cm intra row space).
\end{abstract}

Keywords: Corn, sowing density, silage yield, GAP, Harran Plain

\section{Giriş}

$\mathrm{M}$ ısır dünyada tahıl ekiliş alanı itibari ile buğday ve çeltikten sonra üçüncü, üretim bakımından ise ikinci sırada yer alan önemli bir tahıl bitkisidir. Türkiye'de mısır 658.645 ha alanda, 5.950.000 ton üretilmektedir. Güneydoğu Anadolu Bölgesinde mısır ekim alanları ve üretim miktarı önemli düzeyde artış göstermiş, mısırın ekim nöbeti sistemleri içerisindeki payı her geçen gün artmaktadır. GAP bölgesinde mısır bitkisi 176.874 ha alanda ekilmekte ve 1.544 .385 ton üretilmektedir
(Anonim 2014). GAP sulama projeleri tamamlandığında 1.7 milyon ha alan sulamaya açılacaktır. Bu alan şimdiye kadar Türkiye'de devlet eliyle gerçekleştirilen sulama alanına eşit bir alan olacak ve bu büyük alanda ortaya çıkacak tarımsal üretim artışının gerek GAP Bölgesi gerekse Türkiye için katkısı büyük olacaktır (Öktem 2009).

Şanlıurfa ilinde ise mısır 80.946 ha alanda ekilmekte ve 581.560 ton üretilmektedir (Anonim 2014). GAP bölgesinde özellikle 
Şanlıurfa ve Mardin'de mısır üretiminde önemli artışlar görülmektedir. Yeni sulanabilir alanların üretime açılması, bölge üreticisinin mısır tarımını benimsemesi, yetiştiriciliğinin her aşamasının mekanize olması ve pazarlama probleminin bulunmaması bu artışın nedenleri arasında sayılabilir. Bölgede yeni alanların sulamaya açılmasıyla önümüzdeki yıllarda üretimde artışın devam edeceği beklenmektedir.

Ülkemizde mısırın kullanım alanları gün geçtikçe artmaktadır. Mısır bitkisinin tanesinde $\% 70-75$ nişasta, $\% 8-10$ protein ve $\% 4-5$ yağ bulunmaktadır (Earle et al. 1946). Mısır taneleri içerdiği zengin besin maddeleri nedeniyle hem insan hem de hayvan beslenmesinde kullanılabilmektedir. Hayvan beslenmesinde yem hammaddesi olarak kullanılan mısır, insan beslenmesinde ise doğrudan kullanımı ile birlikte birçok gıda maddesinin üretiminde hammadde olarak kullanılmaktadır. Gıda sanayisinde mısır; nişasta, protein, nişasta bazlı şeker ve yağ kaynağı olarak kullanılmaktadır. Ayrıca bioetonol yakıt olarak kullanımı ile dikkat çekmektedir.

Mısır yetiştiriciliğinde çeşit, ekim zamanı, ekim sıklığı, sulama, gübreleme gibi kültürel uygulamalar verimi önemli ölçüde etkilemektedir. Bitki sıklığının iyi düzenlenmesi diğer üretim faktörlerine göre öncelikli konulardan birisidir. Dekara atılacak uygun tohum miktarı ile, bitkilerin topraktaki elverişli su ve besin maddeleri ile ışık enerjisinden en etkin şekilde faydalanması sağlanmaktadır.

Mısır bitkisinde ekim sıklığı ile ilgili yapılan bazı araştırmalarda optimum bitki sıkığı 7.500$16.500 \mathrm{bitki} / \mathrm{da}$ arasında bildirilirken (Yıldırım ve Baytekin 2003), birim alanda bitki sayısının artması ile silaj veriminde artışın olacağı (Saruhan ve Şireli 2005) belirtilmiştir. Tansı ve ark. (1996), kaba yem üretimi için mısır bitki sıklığını azaltmanın uygun olmadığını, bu nedenle sıra üzeri mesafesinin dar tutulmasının mısır silaj verimini artırdığını bildirmişlerdir.

Kızılşimşek ve ark. (2005) ile Yıldırım ve Baytekin (2003), en yüksek kuru ot veriminin ise $10 \mathrm{~cm}$ sıra üzeri mesafeden elde edildiğini, sıra üzeri bitki sıklığının artmasıyla kuru ot verimininde arttığını bildirmişlerdir. Çarpıcı (2009) ekim sıklığı arttıkça bitki boyunun artı̆ğını, Zeidan et al. (2006) sap kalınlığının azaldığını, Bahadur et al. (1999) artan bitki sıkıklarında yaprak sayısında bir azalma tespit ettiklerini bildirmişlerdir.
Bu çalışma ile Harran Ovası koşullarında silajlık mısır için en uygun ekim sıklığının belirlenmesi amaçlanmıştır.

\section{Materyal ve Yöntem}

$\mathrm{Bu}$ çalışma GAP Tarımsal Araştırma Enstitüsünün Koruklu Talat Demirören Araştırma İstasyonunda 2010, 2011 ve 2012 yıllarında 3 yıl süre ile yürütülmüştür. Deneme tesadüf blokları deneme deseninde 3 tekrarlamalı olarak kurulmuştur. Çalışmada bitkisel materyal olarak Samada-07 melez at dişi mısır çeşidi kullanılmıştır.

Araştırma, Harran Ovası kırmızı-kahverengi toprak grubunda yaygın olarak yer alan Harran toprak serisinde yürütülmüştür. Harran toprak serisi alüviyal ana materyalli düz ve düze yakın eğimli derin topraklar olup, killi tekstürlü, kireçli, organik madde içeriği düşük (\%0.9-0.3), KDK'ları yüksek topraklardır (Dinç ve ark . 1988). Çalışmanın yürütüldüğü yıllarda denemeyi olumsuz etkileyecek toprak ve iklim faktörleri gözlenmemiştir.

Araştırmada 5 farklı ekim sıklığı (14285 bitki/da, 10204 bitki/da, 7937 bitki/da, 6493 bitki/da ve 5494 bitki/da) kullanılmıştır. Ekim sıklıkları sıra üzeri mesafeleri daraltmak suretiyle elde edilmiş olup, $10 \mathrm{~cm}$ sıra üzeri mesafe ile 14285 bitki/da, $14 \mathrm{~cm}$ ile 10204 bitki/da, $18 \mathrm{~cm}$ ile 7937 bitki/da, $22 \mathrm{~cm}$ ile 6493 bitki/da ve $26 \mathrm{~cm}$ ile 5494 bitki/da ekim sıklığı elde edilmiştir. Her parsel 5 metre uzunluğunda 4 sıradan meydana gelmiş olup sıra arası mesafeler $70 \mathrm{~cm}$, ekim derinliği ise $5-6 \mathrm{~cm}$ olarak ayarlanmıştır. Ekim işleminin ardından tav suyu verilmiştir. Vejetasyon süresi boyunca mısıra verilecek gübre miktarları saf olarak 30 $\mathrm{kg} / \mathrm{da}$ azot ve $8 \mathrm{~kg} / \mathrm{da}$ fosfor ve potasyuma tamamlanmıştır. Son toprak işleme uygulamasından önce fosfor ve potasyumun tamamı ve azotun bir kısmı taban gübresi olarak toprağa karıştırılarak verilmiştir. Azotlu gübrenin geri kalan kısmı ise üst gübre olarak üre formunda mısır bitkileri $30-40 \mathrm{~cm}$ boylandığında banda verilmiştir (Kırtok 1998). El çapası ve herbisit ile yabancı ot kontrolü yapılmıştır. Ayrıca yetişme süresi boyunca bitkinin su isteği durumuna göre 8-10 gün ara ile karık sulama yapılmıştır. Silaj hasatları; koçanda süt çizgisi $2 / 3$ oranında olduğunda yapılmıştır.

Elde edilen bulgular JUMP paket programı yardımıyla varyans analizi ve LSD testine tabii tutulmuştur. 


\section{Bulgular ve Tartışma}

\section{Silaj Verimi (kg/da)}

Farklı ekim sıklığında oluşan silaj verimine ait ortalama değerler ve LSD grupları Çizelge 1 'de verilmiştir. Varyans analizi sonuçlarına göre; silaj verimi bakımından yıllar, ekim sıklığı ve yıl $x$ ekim sıkığı interaksiyonu istatistiksel olarak önemli bulunmuştur $(P \leq 0.01)$. Çizelge 1 'de görüldüğü gibi ekim sıklığı bakımından yıllar ortalamasında silaj verimi 5335 ile 6884 $\mathrm{kg} / \mathrm{da}$ arasında değişmiştir. Silaj verimi değeri en yüksek $6884 \mathrm{~kg} / \mathrm{da}$ ile $10 \mathrm{~cm}$ 'lik sıra üzerinde (14285 bitki/da) belirlenirken, en düşük silaj verimi $5335 \mathrm{~kg} / \mathrm{da}$ ile $26 \mathrm{~cm}$ sıra üzeri mesafede (5494 bitki/da) bulunmuştur.

Araştırma bulgularımızı destekler nitelikte Yıldırım ve Baytekin (2003) mısır bitkisinde optimum bitki sıklığının 7.500-16.500 bitki/da arasında bildirirken, Saruhan ve Şireli (2005) birim alanda bitki sayısının artması ile silaj veriminin de artış olduğunu, elde ettikleri bulgulara dayanarak $70 \times 10 \mathrm{~cm}$ ölçülerindeki ekim sıklığın ideal olduğunu bildirmişlerdir. Tansı ve ark. (1996) kaba yem üretimi için mısır bitki sıklığını azaltmanın uygun olmadığını, bu nedenle sıra üzeri mesafesinin dar tutulmasının mısır silaj verimini artırdığını bildirmişlerdir.

\section{Kuru Ot Verimi (kg/da)}

Farklı sıra üzeri mesafelerde oluşan kuru ot verimine ait ortalama değerler ve LSD grupları Çizelge 1'de verilmiştir. Varyans analizi sonuçlarına göre; kuru ot verimi bakımından yıllar, ekim sıklığı ve yıl $x$ ekim sıklığı interaksiyonu istatistiksel olarak önemli bulunmuştur ( $P \leq 0.01)$. Çizelge 1'de görüldüğü gibi ekim sıklığı bakımından yıllar ortalamasında kuru ot verimi 1733 ile 2131 $\mathrm{kg} / \mathrm{da}$ arasında değişmiş̧ir.

Yıllar ortalamasında kuru ot verimi değeri en yüksek $2131 \mathrm{~kg} / \mathrm{da}$ ile 14285 bitki/da (10 cm sıra üzeri) ekim sıklığında belirlenirken, en düşük kuru ot verimi $1733 \mathrm{~kg} / \mathrm{da}$ ile $6493 \mathrm{bitki} / \mathrm{da}(22 \mathrm{~cm}$ sıra üzeri) ekim sıklığında bulunmuştur. Araştırma bulgularımıza paralel olarak Kızılşimşek ve ark. (2005) ile Yıldırım ve Baytekin (2003) en yüksek kuru ot veriminin $10 \mathrm{~cm}$ sıra üzeri mesafeden elde edildiğini, sıra üzeri bitki sıklığının artmasıyla kuru ot veriminin arttığını bildirmişlerdir. Sık yetiştirilen bitkiler sıra üzerini daha erken kapatarak bitkilerin maksimum yaprak alanı değerine daha hızlı ulaşarak bitki sıklığının az olduğu parsellere göre daha fazla ışık tutarak yeşil aksamın daha yüksek olmasını sağlamaktadır. Bu sayede daha fazla vejetatif kitle oluşumu sağlanabilmektedir.

\section{Bitki Boyu (cm)}

Farklı sıra üzeri mesafelerde oluşan bitki boyuna ait ortalama değerler ve LSD grupları Çizelge 2'de verilmiştir. Varyans analizi sonuçlarına göre; bitki boyu bakımından yıllar, ekim sıklığı ve yıl $x$ ekim sıklığı interaksiyonu istatistiksel olarak önemli bulunmuştur $(P \leq 0.01)$. Çizelge 2'de görüldüğü gibi ekim sıklığı bakımından yıllar ortalamasında bitki boyu 276.3 ile $297.06 \mathrm{~cm}$ arasında değişmiştir. Üç yılın ortalamasına göre en yüksek bitki boyu değeri $297.06 \mathrm{~cm}$ ile $10 \mathrm{~cm}$ 'lik sıra üzeri mesafede (14285 bitki/da) belirlenirken, en düşük bitki boyu $276.3 \mathrm{~cm}$ ile $26 \mathrm{~cm}$ 'lik sıra üzeri mesafede (5494 bitki/da) tespit edilmiştir. Bitki

Çizelge 1. Farklı ekim sıklığında yetiştirilen mısır bitkisinde 2010, 2011 ve 2012 yıllarına ait silaj verimi ve kuru ot verimi değerleri ile LSD testine göre oluşan gruplar

Table 1. Silage yields and dry grass yields and LSD groups of corn planted with different sowing densities in 2010, 2011 and 2012

\begin{tabular}{|c|c|c|c|c|c|c|c|c|}
\hline \multirow{2}{*}{$\begin{array}{c}\text { Ekim } \\
\text { sıklığı } \\
\text { (bitki/da) }\end{array}$} & \multicolumn{4}{|c|}{ Silaj Verimi (kg/da) } & \multicolumn{4}{|c|}{ Kuru Ot Verimi (kg/da) } \\
\hline & 2010 & 2011 & 2012 & ORT. & 2010 & 2011 & 2012 & ORT. \\
\hline 14285 & 7307 a† & $6873 \mathrm{~b}$ & 6471 c & $6884 \mathrm{~A}$ & $2179 a$ & $2113 b$ & $2100 \mathrm{~b}$ & $2131 \mathrm{~A}$ \\
\hline 10204 & $6871 \mathrm{~b}$ & $6404 c$ & 5891 e & $6389 \mathrm{~B}$ & 2057 c & $1952 \mathrm{de}$ & 1916 ef & $1975 B$ \\
\hline 7937 & 6346 c & $6166 \mathrm{~d}$ & $5673 \mathrm{fg}$ & 6062 C & $1985 d$ & $1897 \mathrm{fg}$ & $1878 \mathrm{~g}$ & $1920 \mathrm{C}$ \\
\hline 6493 & 5975 e & $5744 \mathrm{f}$ & $5241 \mathrm{i}$ & $5653 \mathrm{D}$ & $1775 \mathrm{~h}$ & $1726 \mathrm{i}$ & $1697 \mathrm{i}$ & $1733 \mathrm{E}$ \\
\hline 5494 & $5583 \mathrm{~g}$ & $5415 \mathrm{~h}$ & $5007 j$ & $5335 \mathrm{E}$ & $1883 \mathrm{fg}$ & $1693 i$ & $1700 \mathrm{i}$ & $1759 \mathrm{D}$ \\
\hline ORT. & $6416 \mathrm{~A}$ & $6120 \mathrm{~B}$ & $5657 C$ & & 1976 A & $1876 \mathrm{~B}$ & $1858 \mathrm{~B}$ & \\
\hline LSD & $\begin{array}{r}\text { YIl } \\
\text { (LSD)78 }\end{array}$ & $\begin{array}{l}\text { SD) }: 44 \\
* * ; Y^{*}{ }^{*}\end{array}$ & $\begin{array}{l}\text { *; Ekim } \\
\text { sık.(LSL }\end{array}$ & $\begin{array}{l}\text { Iğı } \\
36.16^{* *}\end{array}$ & $\begin{array}{c}\text { YII (LS } \\
21.76\end{array}$ & $\begin{array}{l}: 30.51^{* *} \\
\text { Yıl*Ekim }\end{array}$ & $\begin{array}{l}\text { Ekim sıklıc } \\
\text { k. (LSD): }\end{array}$ & $\begin{array}{l}\text { (LSD) } \\
.70^{* \star}\end{array}$ \\
\hline
\end{tabular}

*: ,.05 seviyesinde önemli; **:0.01 seviyesinde önemli; öd: önemli değil

†: Aynı sütunda aynı harf grubuna giren ortalamalar arasında 0.05 seviyesinde önemli farklılık yoktur.

*: Significant at 0,05 level; **: Significant at 0,01 level, öd: non significant

$t$ : There is no significant difference among values annotated with the same letter at the 0.05 level. 

(Zea mays L. indentata) in Harran Plain Conditions"

sıklığı artıkça bitkiler arasında ışıklanma yönünden meydana gelen rekabet bitki boyunun uzamasına sebep olmuştur.

Bulgularımıza benzer olarak mısır bitkisinde ekim sıklığı arttıkça bitki boyunun arttığı bir çok araştırıcı tarafından da bildirilmiştir (Dostalek ve Hruska, 1985; Kolcar ve Videnovic, 1985; Emeklier ve Kün, 1988; Sağlamtimur ve ark. 1994; Tansı ve ark. 1997; Gücük ve Baytekin, 1999; Yıldırım ve Baytekin, 2003; Alıcı ve ark. 2005; Çarpıcı, 2009).

\section{Sap Kalınlığı $(\mathrm{mm})$}

Farklı ekim sıklığında oluşan sap kalınlığına ait değerler ve LSD grupları Çizelge 2'de verilmiştir. Varyans analizi sonuçlarına göre; sap kalınlığı bakımından yıllar ve ekim sıklığı istatistiksel olarak önemli bulunmuştur $(P \leq 0.01)$. Çizelge 2'de görüldüğü gibi ekim sıklığı Çizelge 2. Farklı ekim sıklığında yetiştirilen mısır bitkisinde 2010, 2011 ve 2012 yıllarına ait bitki boyu ve sap kalınlığı değerleri ile LSD testine göre oluşan gruplar

Table 2. Plant heights and stem diameters with LSD groups of corn planted with different sowing densities in 2010, 2011 and 2012

\begin{tabular}{|c|c|c|c|c|c|c|c|c|}
\hline \multirow{2}{*}{$\begin{array}{l}\text { Ekim } \\
\text { sıklığı } \\
\text { (bitki/da) }\end{array}$} & \multicolumn{4}{|c|}{ Bitki Boyu $(\mathrm{cm})$} & \multicolumn{4}{|c|}{ Sap Kalınlığı (mm) } \\
\hline & 2010 & 2011 & 2012 & ORT. & 2010 & 2011 & 2012 & ORT. \\
\hline 14285 & 308.18 bc & 312.66 a† & $270.33 \mathrm{~h}$ & $297.06 \mathrm{~A}$ & 25.22 & 24.31 & 19.83 & $23.12 \mathrm{E}$ \\
\hline 10204 & $304.19 \mathrm{~d}$ & $310.86 a b$ & $268.53 \mathrm{~h}$ & 294.53 B & 27.17 & 25.84 & 21.36 & $24.79 \mathrm{D}$ \\
\hline 7937 & $301.38 \mathrm{de}$ & $304.86 \mathrm{~cd}$ & 262.53 । & $289.59 \mathrm{C}$ & 28.17 & 26.64 & 22.17 & $25.66 \mathrm{C}$ \\
\hline 6493 & 298.25 ef & $296.06 \mathrm{f}$ & $253.23 \mathrm{j}$ & $282.68 \mathrm{D}$ & 30.04 & 28.07 & 23.59 & $27.23 \mathrm{~B}$ \\
\hline 5494 & $294.99 \mathrm{f}$ & $288.20 \mathrm{~g}$ & $245.86 \mathrm{k}$ & $276.35 \mathrm{E}$ & 31.95 & 30.74 & 26.26 & $29.65 \mathrm{~A}$ \\
\hline ORT, & $301.40 \mathrm{~B}$ & $302.53 \mathrm{~A}$ & $260.20 \mathrm{C}$ & & $28.51 \mathrm{~A}$ & $27.12 \mathrm{~B}$ & $22.64 \mathrm{C}$ & \\
\hline LSD & \multicolumn{4}{|c|}{$\begin{array}{c}\text { Yıl (LSD) : } 1.09^{* *} ; \text { Ekim sıklığı (LSD) } 2.04^{* *} \\
\text { YıI"Ekim sık, (LSD): } 3.54^{* *}\end{array}$} & \multicolumn{4}{|c|}{$\begin{array}{c}\text { Yıl (LSD) : } 0.37^{* *} ; \text { Ekim sıklığı (LSD): } \\
0.39^{* *} ; \text { Yıl Ekim sık, (LSD): öd }\end{array}$} \\
\hline
\end{tabular}

*: 0.05 seviyesinde önemli, ${ }^{* *}: 0.01$ seviyesinde önemli; öd: önemli değil

†: Aynı sütunda aynı harf grubuna giren ortalamalar arasında 0.05 seviyesinde önemli farklıık yoktur.

*: Significant at 0,05 level; **: Significant at 0,01 level, öd: non significant

$t$ : There is no significant difference among values annotated with the same letter at the 0.05 level.

Çizelge 3. Farklı ekim sıklığında yetiştirilen mısır bitkisinde 2010, 2011 ve 2012 yıllarına ait yaprak sayısı ve kuru madde oranı değerleri ile LSD testine göre oluşan gruplar

Table 3. Leaf numbers and dry matter ratios with LSD groups of corn planted with different sowing densities in 2010, 2011 and 2013

\begin{tabular}{|c|c|c|c|c|c|c|c|c|}
\hline \multirow{2}{*}{$\begin{array}{l}\text { Ekim } \\
\text { sıklığı } \\
\text { (bitki/da) }\end{array}$} & \multicolumn{4}{|c|}{ Yaprak Sayısı (adet/bitki) } & \multicolumn{4}{|c|}{ Kuru Madde Oranı (\%) } \\
\hline & 2010 & 2011 & 2012 & Ort. & 2010 & 2011 & 2012 & Ort. \\
\hline 14285 & 16.50 a† & $15.52 \mathrm{de}$ & $13.31 \mathrm{gh}$ & $15.11 \mathrm{~B}$ & $28.71 \mathrm{de}$ & $28.76 \mathrm{de}$ & $30.01 \mathrm{ab}$ & $29.16 \mathrm{C}$ \\
\hline 10204 & $16.29 \mathrm{~b}$ & $15.47 \mathrm{e}$ & $13.25 \mathrm{~h}$ & $15.00 \mathrm{C}$ & $28.57 \mathrm{e}$ & 28.33 ef & $29.66 \mathrm{bc}$ & $28.85 \mathrm{C}$ \\
\hline 7937 & $16.54 \mathrm{a}$ & $15.67 \mathrm{~cd}$ & $13.46 \mathrm{fg}$ & $15.22 \mathrm{~A}$ & $29.36 \mathrm{c}$ & $28.77 \mathrm{de}$ & 30.36 a & $29.49 \mathrm{~B}$ \\
\hline 6493 & $16.49 \mathrm{a}$ & $15.71 \mathrm{c}$ & $13.50 \mathrm{f}$ & $15.22 \mathrm{~A}$ & $27.53 \mathrm{~g}$ & $27.77 \mathrm{fg}$ & $29.16 \mathrm{~cd}$ & $28.15 \mathrm{D}$ \\
\hline 5494 & $16.17 \mathrm{~b}$ & $15.56 \mathrm{c}-\mathrm{e}$ & $13.41 \mathrm{f}-\mathrm{h}$ & $15.05 \mathrm{BC}$ & $30.50 \mathrm{a}$ & $28.79 \mathrm{de}$ & $30.44 \mathrm{a}$ & $29.91 \mathrm{~A}$ \\
\hline ORT. & $16.40 \mathrm{~A}$ & $15.59 \mathrm{~B}$ & $13.39 \mathrm{C}$ & & $28.94 \mathrm{~B}$ & $28.48 \mathrm{C}$ & $29.92 \mathrm{~A}$ & \\
\hline LSD & \multicolumn{4}{|c|}{$\begin{array}{c}\text { Yıl (LSD) : } 0.1^{* *} ; \text { Ekim sıklığı (LSD) } 0.09^{* *} ; \\
\text { Yıl }\end{array}$} & \multicolumn{4}{|c|}{$\begin{aligned} \text { Yıl (LSD) : } 0.42^{* *} ; \text { Ekim sıklığı (LSD) } 0.31^{* *} \\
; \text { Y Yıl Ekim sık. (LSD): } 0.55^{* *}\end{aligned}$} \\
\hline
\end{tabular}


önemli bulunmuştur. Çizelge 3'de görüldüğü gibi ekim sıklığı bakımından yıllar ortalamasında yaprak sayısı 15.00 ile 15.23 adet/bitki arasında değişmiştir. Yıllar ortalamasına göre en yüksek yaprak sayısı 15.22 adet/bitki ile $18 \mathrm{~cm}$ (7937 bitki/da) ve 22 $\mathrm{cm}$ (6493 bitki/da) sıra üzeri mesafesinde belirlenirken, en düşük yaprak sayısı 15 adet/bitki ile $14 \mathrm{~cm}$ (10204 bitki/da) sıra üzeri mesafede belirlenmiştir.

Benzer bulgular Sağlamtimur ve ark. (1989) ile Swason and Zuber (1996) tarafindan bildirilmektedir. Saruhan ve Şireli (2005) ile Bahadur et al. (1999) tarafindan belirtilen, artan bitki sıklıklarında yaprak sayısında azalma tespiti bulgularımızla örtüşmektedir. Bulgularımızın aksine Emeklier ve Kün (1988) bitki yoğunluğu artıkça yaprak sayısının artığını belirtmişlerdir.

\section{Kuru Madde Oranı (\%)}

Farklı ekim sıklığında oluşan kuru madde oranına ait ortalama değerler ve LSD grupları Çizelge 3'de verilmiştir. Varyans analizi sonuçlarına göre; kuru madde oranı bakımından yıllar, ekim sıklığı ve yıl x ekim sıklığı interaksiyonu istatistiksel olarak önemli bulunmuştur $(P \leq 0.01)$. Çizelge 3'de görüldüğü gibi ekim sıklığı bakımından yıllar ortalamasında kuru madde oranı \%28.15 ile \%29.9 arasında değişmiştir. Üç yılın ortalamasına göre en yüksek kuru madde oranı değeri \%29.91 ile 5494 bitki/da (26 cm sıra üzeri) ekim sıklığında belirlenirken, en düşük kuru madde oranı $\% 28.15$ ile $(6493 \mathrm{bitki} / \mathrm{da}) 22 \mathrm{~cm}$ sıra üzeri mesafede (5494 bitki/da) bulunmuştur.

\section{Sonuç}

En yüksek silaj verimi $(6884 \mathrm{~kg} / \mathrm{da})$ ve kuru ot verimi $(2131 \mathrm{~kg} / \mathrm{da}) 14286$ bitki/da ekim sıklığında (10 cm sıra üzeri) belirlenirken, en yüksek kuru madde oranı değeri \%29.91 ile $5494 \mathrm{bitki} / \mathrm{da}$ ( $26 \mathrm{~cm}$ sıra üzeri) ekim sıklığında bulunmuştur.

\section{Kaynaklar}

Alıcı S., 2005. Kahramanmaraş Koşullarında Farklı Azot Dozları ile Sıra Üzeri Ekim Mesafelerinin II. Ürün Mısır (Zea mays L.) Bitkisinde Verim, Verim Unsurları ve Bazı Tarımsal Karakterlere Etkisi. (Doktora Tezi). Çukurova Üniv. Fen Bilimleri Enst. Tarla Bitkileri Anabilim Dalı, Adana, $137 \mathrm{~s}$

Anonim 2014.

http://www.tuik.gov.tr/VeriBilgi.do?alt_id=45. (Erişim Tarihi: 30.06.2015)
Bahadur M .M., Ashrafuzzaman M., Chowdhury M F. and Shahıdullah S.M., 1999. Growth and yield component responses of maize as affected by population density. Pakistan Journal of Biological Sciences, 2(4): 10921095

Çarpıcı E.B., 2009. Bitki Yoğunluğu ve Farklı Miktarda Azot Uygulamalarının Stres Fizyolojisi Açısından Silajlık Mısır Yetiştiriciliğinde Değerlendirilmesi (Doktora Tezi). Uludağ Üniv. Tarla Bitkileri Anabilim Dalı, Bursa

Dinç, U., Şenol, S., Sayın, M., Kapur, S., Güzel, N. 1988. Güneydoğu Anadolu Bölgesi Toprakları (GAT) I. Harran Ovası, TÜBITAK, Tarım Ormancılık Araştırma Grubu, Güdümlü Araştırma Projesi Kesin Sonuç Raporu, TAOG, 534, Adana

Dostalek R. and Hruska L., 1985. Effect of crop density on the production in maize seed. Rastlinna Vyroba, 31(10): 1103-1110

Earle F.R., Curtıs J.J., Hubbard J.E., 1946. Composition of the component parts of the kernel. Cereal Chem., 23: 504-512

Emeklier H.Y. ve Kün E., 1988. İç Anadolu'da Sulu Koşullarda İkinci Ürün Tane Mısır ve Silaj Mısır Yetiştirme Olanakları ve Yem Değerlerinin Saptaması. Doğa Tarım ve Orman Dergisi, 12(2): 178-179

Gücük T. ve Baytekin H., 1999. Bozova Sulu Koşullarında İkinci Ürün Olarak Yetiştirilen Silaj Mısır, Silaj Sorgum ve Sorgum Sudan Otu Melez Çeşitlerinde Hasat Zamanının Verim ve Bazı Silaj Özelliklerine Etkisi. Türkiye 3. Tarla Bitkileri Kongresi, 15-18 Kasım, Çayır-Mera Yem bitkileri ve Yemeklik Tane Baklagiller, Cilt III, 178-183, Adana

Kırtok Y., 1998. Mısır Üretimi ve Kullanımı. Kocaoluk Basım ve Yayınevi, İstanbul, s:125-129

Kızılşimşek M., Erol A. ve Kaplan M., 2005. Farklı Bitki Sıklıklarının Silajıı Mısır Çeşitlerinde Yaprak Alanı Gelişimi ve Işık Kullanımı Üzerine Etkileri. Türkiye VI. Tarla Bitkileri Kongresi, 5-9 Eylül 2005, Antalya, Cilt II, Sayfa 1005-1010

Kolcar F. and Vıdenovic Z., 1985. Yield of some maize hybrids depending on plant density and amounts of fertilizers. Arhiv za Poljoprivredne Nauke, 44(155): 315-322

Öktem A., Taş T. ve Öktem A.G., 2009. GAP Bölgesinde Organik Tane ve Silajlık Mısır Yetiştirme İmkânlarının Araştırılması. GAP I. Organik Tarım Kong. 17-20 Kasım 2009, Şanlıurfa, s:1004-1011

Sağlamtimur T., Okant M., Tansı V. ve Baytekin H., 1989. Güneydoğu Anadolu Bölgesi Sulu Koşullarında İkinci Ürün Olarak Yetiştirilen Üç 
Taş et al. "Effect of Different Sowing Densities to Silage Yield and Some Agricultural Characteristics of Corn (Zea mays L. indentata) in Harran Plain Conditions"

Mısır Çeşidinde Bitki Sıklığının Verim ve Bazı Tarımsal Karakterlere Etkisi Üzerinde Bir Araştırma. Çukurova Üniv. Ziraat Fakültesi Dergisi, 4(2): 10-20

Saruhan V. ve Şireli D., 2005. Mısır (Zea mays L.) Bitkisinde Farklı Azot Dozları ve Bitki Sıklığının Koçan, Sap ve Yaprak Verimlerine Etkisi Üzerine Bir Araştırma. Harran Üni. Ziraat Fak. Dergisi, 9(2): 45-53

Sağlamtimur T., Tansı V., Düzgün M., Kızılşimşek M., 1994. Çukurova Koşullarında Mısırın En Uygun Bitki Sıklığının Saptanması Üzerinde Bir Araştırma. Türkiye 1. Tarla Bitkileri Kongresi, 25-29 Nisan, Cilt:1, s:5-8, İzmir

Swason R.A. and Zuber J., 1996. A Case Study of a Failed Organization Development Intervention Rooted in The Employee Survey Process. Performance Improvement Quarterly, 9(2): 42-56
Tansı V., Ülger A., Sağlamtimur T., Kızılşimşek M., Çakır B., Yücel C., Baytekin H. ve Öktem A., 1996. Güneydoğu Anadolu Bölgesi'nde II. Ürün Mısırda Bitki Sıklığı ve Azot Gübrelemesinin Tane ve Hasıl Verimi ve Bazı Tarımsal Karakterlerine Etkisi Üzerinde Araştırmalar. Çukurova Üniversitesi Ziraat Fakültesi Genel Yayın No:158, GAP Yayınları No: 99, Adana

Yıldırım Ö., Baytekin H., 2003. Mısırda Bitki Sıklığının Yeşil Ot ve Tane Verimi İle Bazı Tarımsal Karakterlere Etkisi. Türkiye 5. Tarla Bitkileri Kongresi, 13-17 Ekim 2003. II. Cilt, s. 448, Diyarbakır

Zeidan M.S., Amany A., Bahr El-Kramany M.F., 2006. Effect of $\mathrm{N}$-fertilizer and plant density on yield and quality of maize in sandy soil. Research Journal of Agriculture and Biological Sciences, 2(4): 156-161 